ISBN978-93-86878-09-0

10th International Conference on Language, Humanities, Education and Social Sciences

(ICLHESS-18)

Bali (Indonesia) Jan. 12-13, 2018

\title{
Status of the Third Gender in India: Comparing the Present with Primeval
}

\author{
Ipsita Bajaj $^{1}$ and Kavita Indapurkar \\ ${ }^{1}$ Master Student, Amity University, Noida, Uttar Pradesh, India
}

\begin{abstract}
Human identity is incomplete without gender, as it is an imperative part of self. More so this holds significance in a world that discriminates on this basis. However existence of third gender is primitive and can be traced back to the very advent of human civilization. Excerpts from Indian mythology confirm their existence in "Treta" as well as "dwapar" yug. It is difficult to believe that even now, in the modern times this third gender is still awaiting some of its most fundamental rights not only in India but all over the world. In India, most commonly used term to denote the third gender is 'hijra'. Studies reveal that this term is only South Asian specific and whatever work is done on third gender outside of the Indian sub-continent does not include 'hijra' as a part of third gender. This leaves this community further more excluded and secluded from the world forum. Being one of the oldest Indian communities, their evolution through the years in modern India is noteworthy. It is a matter of fact that common people who find themselves to be a part of the commonly classified sex do not know much about the third gender because of the very fact that 'sex' is taboo in this part of the world. Hence all those who do not identify themselves to be either male or female are referred to as 'hijra' in India. Even though discrimination on the basis of caste, creed, and gender is made illegal by the Indian Constitution, citizens still face this prejudice, and characteristics like ability, potential and passion to work are ignored. There exist laws that are in place to prevent this from occurring, but they are not strictly followed. It, therefore, does not require any justification to mention the plight of the third gender or 'hijra' community in India. One of the features of the texture of Indian society was that of occupational stereotyping. The 'hijra' community traditionally was meant to earn by giving blessings on auspicious occasions like birth or marriage. Later with the distortion of the cultural knowledge and misrepresentation of traditions in the patriarchal society, they were used in prostitution and left to begging otherwise. As a result of this stereotyping, they only add to the grey economy of the country. However, with an increase in public awareness, and with their own desire to be empowered, and to assertively break the barriers of 'convention', they are standing up for their rights. As a result of which some of their fundamental rights have now been restored. The present paper makes an attempt to understand the plight of this 'left out' community in India, their status in modern India and also bring out the evolution of this community in India.
\end{abstract}

Keywords: Hijra, employment, grey economy, Occupational stereotyping

\section{Conceptual Background}

Our older teachings point towards 'oneness', which has been carried forward since centuries and is followed even today. When we occasionally say and believe that a couple is a unit, the male and female unite together to form a unit. two hodies and one soul and so on. These savings are nothing hut the reflections of our older wisdom. The epitome of this concept is the form of 'Ardhanarishvara' (Sanskrit: अर्धनारीश्वर, Ardhanārīśvara) where lord Shiv and goddess Parvati are depicted in two halves as one. There are mythological texts that also talk about transformation of male into a female, and vice versa. The female form of Lord Vishnu, 'MOHINI', who by her feminine tantrums seduced the demons, fooled them and devoided them from the holy drink- the 'amrut'. In this avatar, Mohini and lord Shiva met and 'rudra' was formed which after centuries was born as 'Hanumana' in the 'treta' yug. (Devdutt Pattanaik, 2006) Amba in 'Mahabharata' left her 'femininity' and transformed herself (into a male named Shikhandi) to take revenge for her insult from the very famous 
'Bhishma'. There are many similar mentions in our Puranas and Vedas that date back to 2000 BC. These are famous instances which indicate that these occurrences must have been common in that period. However, contemporary society fails to recognize the commonality of the existence of the third gender, in short those who do not categorize themselves as either males or females. Another instance comes from the legend of Ramavana where while leaving for exile. Rama reauested all not to follow him further and ordered ("अयोध्या के सभी नर नारी अपने घरो को लौट जाये”) "All men and women of Ayodhya may return to your home. We promise, we will be back after fourteen years." Everyone left on this order of their beloved Prince, except eunuchs, who waited on the outskirts of Ayodhya for 14 years, as they were neither male nor female. Ram on his return was surprised to find them still waiting. He then bestowed them with the boon that whatever blessings they give would be fulfilled. This suggests that the third gender prevailed commonly and demonstrates that the eunuchs in that era wished to be categorized separately from men and women. (Vishala Katta, 2016)

More recently, Malik Kafur (1296-1316) was a eunuch slave who went on to become a general in the army of Alauddin Khilji, the ruler of the Delhi sultanate (Delmar Thomas C. Stawart) Similarly "Khusrau Khan, Sultan Kutbuddin Mubarak Khilji's favourite commander, who killed the sultan in 1320 and occupied the throne briefly was a eunuch too.”(M. A. Khan, 2009)

In India, the third gender are clubbed under one umbrella and are termed as 'hijras', and these have always been very much part of our social system. The shift in the perceptions and opinions during the years is interesting to note. For instance, they held important positions in history, but today, people hardly accept them. The acceptance for 'hijras' in the past is not aligned with the present thought. In the contemporary scenario, their existence is considered to be a taboo. The present paper makes an attempt to add to the existing limited literature on the third gender and others who recognize themselves belonging to the gender troubling category, their problems, their present status and their fight to be a part of the mainstream.

\section{Objectives}

The objectives of this paper are:

1. To understand and clearly bring out how the third gender is as primitive as other two genders.

2. What is article 377 and how it has a role to play in society and what is the other side of this.

3. How 'hijra' community is different from the third gender, and how the rest of the world classifies it.

4. To look for ways to empower the 'hijra' community in their present condition.

\section{Common Terminologies}

Gender identity is associated with the internal sense of being a man, woman, or anywhere along the gender continuum. 'Hijras' or Kinner are some specific words used in South Asia for the transgender community. This is irrespective of knowing whether a person has undergone castration or was born in with genital defects. Whereas, 'transgender' is an inclusive word used for describing a range of behaviours, expressions, and identifications which pose a challenge to the binary sex system. "This term is also used as a way to identify cross-gender individuals who are not seeking sex reassignment surgery" (Lev, 2004). The gender fluid or troubled categories have a sense of overlapping gender identities, which generally do not fit in the rigidly constructed notions of gender. Whereas, Gender expression refers to the ways we signal our gender to society through body language, style and behaviours and the way these are perceived by those around us. Transsexual is used by the clinical/medical practitioners for people with cross-gender identifications and who look forward to sex-reassignment surgery (SRS).

\section{Literature Review}


The 1951 Census of India (first census after independence and Partition of India) was the 9th in a series of censuses which included categorization of the population on the basis of religion and language, further it was segregated on the basis of minorities and backward classes etc. It seems to be very strange to know that only on May 30, 2014 the first official count of the third gender in India was announced to be 4.9 lakh, although the actual number is estimated to be 7-8 times more (The Times of India, 2014). The reluctance of recognizing themselves as the third gender is the biggest reason for that crevice in the numbers. Of these, only $46 \%$ were literate; $38 \%$ were working, of which only $65 \%$ found work for more than 6 months in a year. Evidently, they are being ignored in our society to such extents that the population census does not even include an approximate figure of the third gender.

Our constitution guaranteed Right to Personal Dignity, Right to Education, Right against discrimination to every person and Right to Privacy. But due to lack of recognition and probably their own urge for the same, 'hijras' never enjoyed these rights. It was only in 1994 that they were granted voting rights in India. In 2014, in the National Legal Services Authority v/s Union of India case the Supreme Court of India declared these people to be included in the category of "third gender" and affirmed that the fundamental rights granted under the Constitution of India will be equally applicable to the third gender, and gave them the right to self-identification of their gender as male, female or third gender. The Transgender Persons (Protection of Rights) Bill 2016, proposed that a person needs to obtain a certificate of identity in order to invoke the rights of a transgender.

The Supreme Court in 2014 declared transgender people to be a "socially and educationally backward class," entitling them to affirmative action in education and government employment. These far-reaching decisions should lead to rapid improvements in the legal, social, and economic status of transgender people, but due to lack of provisions on state and national level, they still hold a very bleak status. Despite the court recognizing the rights of the transgender community, their sexuality continues to be criminalized under the IPC Section 377 of the Indian Penal Code which prohibits "carnal intercourse against the order of nature with any man, woman or animal". Also, IPC Section 375 and Section 376 exclude both men and third gender from the category of natural victims of sexual violence. To put it simply, the law does not support/accept the idea that third gender can also get raped or sexually abused. This has also lead to serious debates and discussions.

There is a dearth of literature and research in the areas of their employability and employment as well as their experience regarding the same. There is hardly any evidence to support whether the third gender is involved in the formal job sectors. However, there is evidence to support the fact that there exists occupational stereotyping in specific jobs/professions attached to the male and female sexes of the society and this can be extended to exist for the third gender as well. With women being regarded as the second sex (Simone de Beauvoir, 1949), there are enough evidences across the world that suggest prevalence of discrimination at various levels including discrimination in the professional set-up, the trans community has to go a long way in this regard as they are classified as 'third' sex. (International Labour organisation, 2017)

In the Indian Subcontinent, "Some of them earn a fair amount through sex work but face violence and violations, and have to pay off cops and goondas (hired thugs). So, while they do want more jobs in mainstream organizations, the job has to ensure a living wage and they should know that they will be secure and accepted. Otherwise, they would be reluctant to make the switch," says Shubha Chacko, founder of Solidarity Foundation, a non-profit organisation that works for transgender rights. The authors look forward to conduct empirical research to understand the psyche of the people across genders and the change in their attitudes towards such violations in India, so that policy measures may be taken towards improving their condition.

\section{Theories}

The lack of a synonym for the word 'hijra' has resulted in the failure of the gender theories from the West to recognize this South Asian community. Annamarie Jagose's Queer Theory: An Introduction in 1997, was a breakthrough, when the word Queer was used as a slang for homosexuals and for homophobic abuse. But over the period of time, it has become an umbrella term for those set of culturally marginalized identities that may 
have a different sexual orientation than that of the mainstream. According to Jagose (1996), "Queer focuses on mismatches between sex, gender and desire." Although the Queer theory which is an idea developed in the West argues on the various aspects of gender, sex, desire and the mismatch between them, Queerness is associated with gay subjects, lesbian and bisexuality and it also talks about issues associated with cross-dressing, intersex bodies and identities, gender ambiguity and gender-corrective surgery. The 'hijra' community, however, is specific to South Asia, which these Eurocentric labels fail to recognize. The 'hijra' community is generally identified here as a male body dressed in female attire and has feminine mannerisms that looks quite 'odd' for a masculine body. They also have all other bodily features that resemble that of males, like areas of hair growth etc. This all makes them look quite different.

The 'Transition' phase is a long process, when a person does not feel in tune with the sex that an individual is born with at the time of birth. It takes about two years during which a person 'moves' socially, mentally and physically from one gender to another. Added on, for 6 months that person also undergoes hormone therapy which is followed by a small surgical procedure called 'Nirvana' (voluntary castration) that is finally performed when the person is 'ready to lead a life of a Hijra'. (Asmita Bhattacharyya, Sudeep Basu, 2017). This is the process of transformation or evolution of a person from a particular sex to 'hijra'. Presently, 'sex' (intercourse) itself is a taboo among the societies in this part of the world, talking of this kind of orientations with respect to sex is further frowned upon.

\section{Their Lone Fight}

A country which scores poorly on the Human Development Index in context to crime against the women, there is no sign of the extent of the violations against the third gender. The first transgender person to represent Asia Pacific in the UN is from Uttar Pradesh, India. Laxmi Narayan Tripathi who is known as the Hijra Guru is on the boards of various NGOs, that work for the trans community. She has on numerous occasions said that "We are as normal as anyone else". And there is no doubt about it. Everyone is human. If their preferences and choices are not similar to the social constructs created by a few individuals, it does not mean that they deserve to be marginalised. Similarly, Shabnam "Mausi" Bano, the first transgender Indian or 'hijra' was elected as member from 1998 to 2003, in the Legislative Assembly Elections of Madhya Pradesh.

Recently, there is a very interesting and encouraging case of Monika Das, the banker who after years of anxiety, finally came out to her workplace as a transgender at the Kankarbagh branch of Syndicate Bank in Patna, where she's a clerk. She laughs away comments like "should she be called 'sir' or 'ma'am". In June 2015, she submitted an affidavit to the bank stating that she is transgender. She acknowledges the fact that "It was the biggest day of my life. I no longer had to pretend to be someone I was not". The steady support from her family helped her in adapting to the change. "I am very fortunate that my mother never discriminated between my two brothers and me," recalls Das, who has a Masters in Law from Patna Law College. Throughout her education, despite dressing as a man, she was subjected to bullying and teasing. But being miserable about one's identity is no good either. This story encourages all those who look forward to a normal existence of a transgender/ hijra in the fabric of the Indian society, and only awareness can make it easier for all of us to accept them as they are without fussing around pressing what they ought to be.

It's high time that our society differentiates between a person fit for employability and the sex assigned to the person at birth or otherwise. Vikramaditya Sahai remarks that "Bodies are bodies only as much as they are intelligible to the norms of recognition, i.e., the body must conform to the norm of the body else it is not recognized as a body." (“Bodies Beyond Rights”, 2014).

\section{Efforts by the Society}


Definitely very slowly and with a lot of debate on social platforms, this has been accepted as one of the major human rights of an individual to express his gender orientation. Odisha is the first state to provide social welfare benefits to the transgender with Below Poverty Line (BPL) cards, free housing and 100 days of work. (Jatindra Dash, 2016). On a national level, transgender have the option of selecting eunuch ("E") on passports and on certain government documents. The Election Commission (EC) forms too have a separate column 'O' for 'Others' (Transgender or Hijras) in the voter enrolment and registration forms. Also, the Unique Identification Authority of India (UIDAI) has recognized the transgender community. Enrolment forms of the UIDAI have a third column of 'T', for 'Transgender'. (Sreoshi Sinha, 2016).

As we write this article, we came across two initiatives aimed at their inclusiveness in the mainstream. One, a prominent school of Delhi took the courage to appoint a transgender to join the school as a teacher, keeping aside the gender orientation and just considering his qualifications and quality. "Despite continuous counselling and sensitizing children, parents and other teachers in the school, he was being mocked and called names which eventually forced him to resign." recalls the principal.

Kerala Metro Limited launched its metro train project in June 2017. Under the Kudumbashree programme, they employed around 23 people from the transgender community. (John L. Paul, 2017) They posted a video on social media where some of the transgender employee made a passionate appeal, "When you look at me, don't look twice. I want you to look at me, and just see a person doing a job." Kerala was also the first state to formulate policies for transgender. Even though these initiatives boast inclusiveness, they are still maligned by the narrow-mindedness of the society.

\section{Section 377 of Indian Penal Code}

The much debated issue is the section 377 of IPC, which criminalizes sexual activities with the same sex. When one talks about the plight of the transgender community, this section is seen as a violation of their rights. It needs to be accepted that sex between adult individuals should be 'consensual' and not defined on the sole idea of procreation. According to Maslow's Hierarchy of needs (1943), sex is one of the basic physiological needs of a person and they should have the freedom to opt for their preferences. However, the section also criminalizes bestiality, which should not be equated with sex with a human. Definitely, critics are of the view that the section should be put for modification so that a mature adult may pursue their sexual orientation.

\section{Discussion}

Since this community is ostracized, victimized and lives on the fringes of the society, it requires specific policies aimed at bettering their conditions. Just like strict laws have been formulated to support the weaker sections of the society, which includes victims of dowry deaths, sexual harassment, child marriage and Protection of Children from Sexual Offences Act. Similarly, people belonging to the gender non conforming category should be paid attention to and not be considered as third class citizens. Constant reinforcement of the fact that being 'other' and not identifying with the gender binary is not unnatural and it is one's right to decide and pursue one's sexual orientation. This view should be evoked by scholars. Moreover, the term 'hijra' being exclusive to South Asian culture makes it difficult for specifically Western thinkers to articulate and present their arguments which would and should include Hijras.

Media also needs to play a very strong role as a means to sensitize, spread awareness and promote equal rights for the transgender community. The fact that they are humans, counselling, lessons on transgender entrepreneurial efforts are efforts that the government and community leaders should be encouraged to take up at the grass root level. There was a time widows were not accepted, change has come, when a narrow-minded society can accept such a revolution, and then the revival of our traditional values and ethics towards the third gender can also be brought about. The inclination towards gender equality that provides them dignity and right to earn their livelihood is to be brought about. Basic rights like marriage, transferring of property and adopting 
children, which are governed by statutes based strictly on a man-woman binary in India should be altered with the changing times.

In 2015, the Rajya Sabha passed a bill to increase educational and economic opportunities for the country's transgender population and offer protection from violence, including sexual assault. The bill was intended to strengthen the 2014 Supreme Court ruling but it is still on hold. Sex reassignment surgery (SRS) is a way to resolve sex-gender conflict. It is noted that only a fraction of 'hijras' actually pursue SRS. Due to high cost that the private clinics demand and social stigma, these people tend to turn to quacks or unqualified doctors which may be fatal at times. Trapped in poverty and destitution is high among this community. Other issues that require special attention include: separate bathrooms and toilets for third gender. The ministry of water and sanitation released a circular where they specified that these people can choose any between male and female as per their comfort level. This means that the common people have to accept such a provision. Are we ready to accept and welcome such thought, is definitely a big question that awaits an answer...!

\section{References}

[1] Rema Nagarajan, (2014). First count of third gender in census: 4.9 lakh, The Times of India. Retrieved from http://www.indiatimes.com/.

[2] Jatindra Dash, (2016): India's Odisha state becomes first to give welfare to transgender community. Retrieved from https://www.reuters.com/.

[3] M. A. Khan, (2009): Islamic Jihad: A Legacy of Forced Conversion, Imperialism, and Slavery, iUniverse. (Print)

[4] Rajorshi Das, (2015): Representation and Categorization: Understanding the Hijra and Transgender Identities through Personal Narratives, Volume VII, Number 3, 2015, Rupkatha Journal General Issue.

[5] Delmar Thomas C. Stawart (2012): Malik Kafur, Dicho Publisher. (Print).

[6] Devdutt Pattanaik, (2006): Shiva to Shankara: Decoding the Phallic Symbol, Indus Source.(Print)

[7] Vinay Lal, (1999): Not This, Not That: The Hijras of India and the Cultural Politics of Sexuality, No. 61, Out Front: Lesbians, Gays, and the Struggle for Workplace Rights (Winter, 1999), pp. 119-140.

[8] Gurvinder Kalra, (2011): Hijras: the unique transgender culture of India, International Journal of Culture and Mental Health Vol. 5, Iss. 2,2012.

[9] Richard Guy Parker, Peter Aggleton, (1999): Culture, Society and Sexuality, Psychology Press.

[10] Aniruddha Dutta, Raina Roy, (2014): Decolonizing Transgender in India: Some Reflections TSQ: Transgender Studies Quarterly (2014) 1(3): 320-337; doi:10.1215/23289252-2685615.

[11] Vishala Katta, (2016): A Window Seat, Leadstart Publishing Pvt Ltd. (Print)

[12] Revathi. A., V. Geetha, (2010): The Truth About Me: A Hijra Life Story. trans. V. Geetha. India: Penguin Books. (Print)

[13] Annamarie Jagose, (1997): Queer Theory: An Introduction. (Print)

[14] A. I. Lev, (2004). Transgender emergence" Therapeutic guidelines for working with gender- variant people and their families. Binghamton, NY: Hawthorn Clinical Practice Press.

[15] Vikramaditya Sahai, (2014): Bodies Beyond Rights, In Plainspeak, A digital magazine on sexuality in the Global South.

[16] Asmita Bhattacharyya, Sudeep Basu, (2017): Marginalities in India: Themes and Perspectives, Springer. (Print)

[17] Sreoshi Sinha, (2016): Social Exclusion of Transgender in the Civil Society: A Case Study of the Status of the Transgender in Kolkata, International Journal of Humanities \& Social Science Studies.

[18] John L. Paul (2017): In a first, transgenders get jobs at Kochi Metro, The Hindu. Retrieved from http://www.thehindu.com/.

[19] Simone de Beauvoir, (1949): The Second Sex. (Print)

[20] International Labour Organisation (2017): WORLD EMPLOYMENT SOCIAL OUTLOOK, TRENDS FOR WOMEN 2017. (Print) 